\title{
DISAGGREGATION AND FORECASTING OF THE MONTHLY INDONESIAN GROSS DOMESTIC PRODUCT (GDP)
}

\author{
Profita Sumunar Luthfiana ${ }^{1}$, Nasrudin ${ }^{2}$
}

\begin{abstract}
Gross Domestic Product (GDP) is considered as the best measure of economic performance. However, in Indonesia, the GDP is presented in quarterly aggregate value. As a result, the monthly economic outlook is known, and analysis with other monthly economic variables becomes limited. Therefore, this study will disaggregate quarterly GDP into monthly GDP and its forecasting by using one of the coincident indicators which are monthly Production Index of Large and Medium Manufacturing (industrial production index). Disaggregation is done on National GDP data of Indonesia period 2000/I to 2016 / IV, whereas forecasting is made on monthly and quarterly GDP 2017. This study uses a combination of the simple linear regression model and ARIMA model with some modifications. The disaggregation result indicates that the monthly GDP moves volatile and has a different pattern between quarter. Also, the monthly GDP disaggregation and forecasting are proven that can be used by industrial production index that becomes a coincident indicator. GDP 2017 shows that the highest quarterly GDP will have occurred in the third quarter, whereas the highest monthly GDP will have occurred in June (second quarter). The result of disaggregation can be used further to the study of economic outlook will be more comprehensive.
\end{abstract}

Keywords: disaggregation, monthly GDP, coincident indicator, industrial production index, ARIMA

JEL Classification: C22, C53, E01, E32

1 Staff of Statistic Indonesia Government Office

2 Lecturer at Sekolah Tinggi Ilmu Statistik (STIS) Jakarta (Coresponding Author; nasrudin@stis.ac.id) 


\section{INTRODUCTION}

Economic, monetary and banking policies are inseparable from the growth dynamics of a developing economy. Gross Domestic Product (GDP) is considered to be the best measure in displaying the economic performance of a country ${ }^{3}$. It summarizes all economic activity in particular units of money over a specified period. As an indicator that represents a comprehensive economic development, the GDP is not only the basis for determining government policy but also a need for businesspeople, economists, and analysts. The Central Bureau of Statistics (BPS) was able to present data of Quarterly GDP with a lag presentation of fewer than two months. However, the dynamic of the economic movement is sudden and quick, allowing for changes in the indicator from month to month. As the leading indicator, the quarterly GDP was not able to describe the economic movement on a monthly basis.

In some countries, the monetary policy can be formulated in less than three months. Thus, it is necessary to understand what happened within the quarter ${ }^{4}$. In Indonesia, at least once a month, Bank Indonesia as the central bank conducts a Board of Governors Meeting (BGM) to establish a general policy on monetary affairs ${ }^{5}$ The determination of macroeconomic policy should be based on actual and up to date state, which fluctuates from month to month, to anticipate the shock/ pressure that occurs. Government policies made at an inappropriate time could lead to a lack of potential economic growth and even recession ${ }^{6}$.

The research on economic, monetary and banking policy-making is often confronted with different series of data. Financial, monetary and banking indicators such as interest rates, money supply, inflation, lending, foreign direct investment, and similar indicators are available monthly. If the data on the GDP is only available quarterly, then the analysis will be limited and insufficient. From a statistical point of view, time series patterns are often not well captured when the data series are short, so the estimates and forecasting results are less precise. Therefore, monthly GDP data is critical to analysis, research and economic, financial, monetary and banking policymaking.

On the other hand, available short-term (monthly) indicators reflect the actual economic changes that occur ${ }^{7}$. In the business cycle theory, the indicators are called the coincident indicators which are variables that correlate with current economic

3 N. G. Mankiw, (2011), Macroeconomics (7th ed), Worth Publishers, New York.

4 Bank Indonesia. "Board of Governors Meeting Schedule (RDG)" http://www.bi.go. id/id/ruang-media/agenda/rapat-dewan-gubernur/Default.aspx, 2017

5 Bank Indonesia. "Board of Governors Meeting Schedule (RDG)" http://www.bi.go. $\mathrm{id} / \mathrm{id} /$ ruang-media/agenda/rapat-dewan-gubernur/Default.aspx, 2017

6 Rianto and Hendranata, Anton. "Updating Leading Indicators of the Indonesian Economy." Final report by the Ministry of Finance of the Republic of Indonesia Fiscal Policy Office Macroeconomic Policy Center, 2014, p. 1.

7 Bruno et al. "Short-run GDP Forecasting in G7 Countries: Temporal Disaggregation Techniques and Bridge Models". Europan Communities Working Paper Studies, July 2005. 
activity $^{8}$. Coincident indicators will move in line with the reference series that is usually represented by the value of the GDP. Several indicators are suspected to be coincident indicators such as industrial production, sales price, unemployment rate, and real income (Moauro and Proietti, 2005). In Indonesia, the data that could be possibly used is the production index of Large and Medium Manufacturing Industry (IBS) as it is observed monthly, available in long series, and up to date.

The monthly IBS production index is considered as a coincident indicator so that it has the same movement at the same time as the GDP. Therefore, by utilizing the same movement pattern, the disaggregation and forecasting of monthly GDP will be done with the monthly IBS production index.

Thus, the objectives of this research are: (1) to conduct quarterly GDP disaggregation into the monthly GDP in Indonesia; (2) testing the conformity of the IBS production index as a coincident indicator; (3) forecast quarterly and monthly GDP of 2017.

\section{THEORY}

Gross Domestic Product (GDP) is the amount of value added generated by all business units within a given country or the total value of final goods and services produced by all economic units. The release of GDP is always awaited by all parties because GDP is a barometer of the ups and downs of a country's economy. As a macroeconomic indicator, analysts, politicians, mass media, the business community, and the public await the release of the GDP as a form of anticipation of the economic policies undertaken ${ }^{10}$.

According to Mankiw, the GDP can be used as reference series in business cycle theory. The business cycle is the rise and fall of many simultaneous economic activities that will reoccur in the future. Reference series is a variable that can describe economic conditions in aggregate. Three kinds of indicators are known in the business cycle analysis, namely leading, coincident, and lagging indicators. Leading indicator is an indicator that moves ahead of coincident or reference series. Coincident indicators are indicators that move along the reference series. Lagging indicator is a moving indicator (lag) of coincident or reference series ${ }^{11}$.

The actual economic growth is assumed to have movement in line with the series/other indicators so-called co-movement. Thus, coincident indicators are variables that correlate with current economic activity (actual). Because it has the same movement at the same time, the coincident indicator will represent the actual state of the economy in real time. Indicators that are considered to be sources of

8 Mongardini, Joannes and Saadi-sedik, Tahsin. "Estimating Indexes of Coincident and Leading Indicator: An Application of Jordan," IMF Working Paper, August 2003.

9 Central Bureau of Statistics. "Understanding National Income" https://www.bps. go.id/Subjek/view/ id/11\#subjekViewTab1 I accordion-daftar-subjek1

${ }^{10}$ Sutomo, Slamet, (2016), Data System and Tools of Macroeconomic Analysis, CorBooks, Bandung.

${ }^{11}$ Rianto and Hendranata, Anton., op.cit., p. 4. 
movement from the actual state of the economy include industrial production, sales, unemployment, and real income.

Meanwhile, Friedman in 1962 disaggregated on a variable by utilizing other variables that are considered to correlate with the variable on which the disaggregation is to be performed ${ }^{12}$. The temporal disaggregation method is used to disaggregate from series with low to high-frequency series. For example, from yearly to quarterly or from quarterly to monthly. Disaggregation will result in the consistent, average, and consistent beginning or ending numbers between high and low frequencies.

For example, the temporal disaggregation, from now on is referred to as disaggregation, is carried out from the quarterly series (low frequency) to the monthly series (high frequency) by utilizing other related variables (indicator series). First, we determine the initial estimate of the monthly value calculated from the series indicator. Then, calculate the difference between the actual monthly value and the estimated value of quarterly time observation. Furthermore, the difference is distributed to the series difference with monthly time observation. The disaggregation equation is denoted as follows ${ }^{13}$.

$$
\hat{z}=p+D u_{l}
$$

with:

$\hat{z} \quad$ : series from disaggregation results;

$p$ : initial estimation series;

$D$ : distribution matrix;

$u_{l}$ : the difference between the actual value and the initial monthly estimate in quarterly time observation

Here is a summary of some of the methods that can be used for disaggregation.

Table 1.

Some Disaggregation Methods

\begin{tabular}{lll}
\hline \multicolumn{1}{c}{ Methods } & \multicolumn{1}{c}{ Initial estimation Series $(\mathrm{p})$} & \multicolumn{1}{c}{ Analysis } \\
\hline Cubic Spline & With or without indicator series & Regression \\
Denton, Denton-Cholette & With one indicator series & $\begin{array}{l}\text { Regression } \\
\text { time series }\end{array}$ \\
Chow-lin, Fernandez, Litterman & with $>=1$ indicator series & $\begin{array}{l}\text { Regression } \\
\text { time series }\end{array}$ \\
\hline
\end{tabular}

Source: Sax, Christop \& Steiner (2013) and Katz (2006).

${ }^{12}$ Guerro, M. Victor. "Monthly Disaggregation of a Quarterly Time Series and Forecast of Its Unobservable Monthly Values," Journal of Official Statistics, Vol. 19, No. 3, 215235.

${ }^{13}$ Sax, Christop and Steiner, Peter. "Temporal Disaggregation of Time Series", The R Journal, December 2013, 80-87. 
The Cubic Spline method is often used in the process of changing the data frequency. The interpolation method uses the function approach as a connecting polynomial. However, the Cubic Spline has the disadvantage that the interpolation results, before the first knot (point change function) and after the last knots, tend to be linear (Katz, 2006). Meanwhile, the Chow and Denton method use the primary time series analysis. However, according to Guerrero (2003), the determination of the autocorrelation structure is still subjective.

As a consequence, Guerrero, a professor of statistics in 2003, developed a technique of disaggregation based on previous studies. He assumes that $\left\{Z_{t}\right\}$ with $t=1, \ldots, m n$ is a time series data that which is unobserved/unmeasured (high frequency). $n \geq 1$ represents the sum of all observed periods (low frequencies), e.g., quarterly. $m \geq 2$ shows the number of frequencies in the observed period such as the number of months in a quarter. It is assumed that $\left\{W_{t}\right\}$ is a series from the preliminary estimates from unobserved data that do not allow stationary. Next, the relationship between $\left\{Z_{t}\right\}$ and $\left\{W_{t}\right\}$ becomes as follows.

$$
Z_{t}=W_{t}+S_{t}
$$

With $S_{t}$ being the difference from unobserved stationary data with zero average. The model comes with the following assumptions.

The Autoregressive Moving Average (ARMA) model can explain the pattern of series $\left\{S_{t}\right\}$ with the following equation.

$$
\phi_{S}(B) S_{t}=\theta_{S}(B) e_{t}
$$

with $\phi_{S}$ and $\theta_{S}$ representing the $\mathrm{AR}(\mathrm{p})$ and MA (q) polynomial models expressed in the form of backshift notation (B) as follows.

$$
\begin{aligned}
& \phi_{S}(B)=1-\phi_{S, 1} B-\phi_{S, 2} B^{2}-\cdots-\phi_{S, p} B^{p} \\
& \theta_{S}(B)=1+\theta_{S, 1} B+\theta_{S, 2} B^{2}+\cdots+\theta_{S, q} B^{q}
\end{aligned}
$$

With the unit root being outside the unit circle and satisfying the invertibility conditions. $\left\{e_{t}\right\}$ is white noise with zero average and variance $\sigma_{e}^{2}$.

Series $\left\{W_{t}\right\}$ can be expressed with the autoregressive integrated moving average (ARIMA) model as follows.

$$
\phi_{W}(B) d(B) W_{t}=\theta_{W}(B) u_{t}
$$

With $d(B)$ as the differencing rate so $\left\{d(B) W_{t}\right\}$ is stationary. $\phi_{W}(B)$ and $\theta_{W}(B)$ have unit root outside the unit circle. $\left\{u_{t}\right\}$ is white noise with zero average and variance $\sigma_{u}^{2}$. Between $\left\{e_{t}\right\}$ and $\left\{u_{t}\right\}$ there is no correlation.

The equation of the difference value $(S)$ can be written as follows.

$$
S_{t}=\psi_{S}(B) e_{t}
$$


With $\psi_{S}(B)=1+\psi_{S, 1} B+\psi_{S, 2} B^{2}+\cdots$ as a real polynomial MA obtained from the relation $\psi_{S}(B)=\frac{\theta_{S}(B)}{\phi_{S}(B)}$. Thus, the above equation can be written in matrix form as follows.

$$
\boldsymbol{S}=\boldsymbol{\Psi}_{S} \boldsymbol{e}
$$

With $\boldsymbol{S}=\left(S_{1}, \ldots, S_{m n}\right)^{\prime}$ and $\boldsymbol{e}=\left(e_{1}, \ldots, e_{m n}\right)^{\prime} \boldsymbol{\Psi}_{\boldsymbol{S}}$ representing the lower triangular matrix of $m n \times m n$ size with the main diagonal being one (1), the first sub-diagonal is worth $\psi_{S, 1^{\prime}}$ the second sub-diagonal is worth $\psi_{S, 2^{\prime}}$ and so on.

Series at time observation which is in the unobserved value unit (mean), i.e. $\left(Y_{1}, \ldots, Y_{n}\right)^{\prime}$, can be written as follows:

$$
Y_{i}=\sum_{j=1}^{m} c_{j} Z_{m(i-1)+j}
$$

with $i=1,2, \ldots, n$.

$c_{j}$ is a constant whose value depends on the type of disaggregation. Disaggregation has a type of distribution if $Y_{i}$ is a flow variable so that $\boldsymbol{c}^{\prime}=\left(c_{1}, \ldots, c_{m}\right)=(1, \ldots, 1)$. For a flow variable with quarterly time observations, the disaggregated vector is expressed by $\boldsymbol{c}^{\prime}=(1 / m, \ldots, 1 / \mathrm{m})$ with $m=3$ stating the number of months in a quarter. Next, the $\mathbf{C}$ matrix (aggregation matrix), $\mathbf{Y}$, and $\mathbf{Z}$ are defined as follows.

$$
\begin{aligned}
& C=I \otimes c^{\prime} \\
& Y=\left(Y_{1}, \ldots, Y_{n}\right)^{\prime} \\
& Z=\left(Z_{1}, \ldots, Z_{m n}\right)^{\prime}
\end{aligned}
$$

With $I$ as the identity matrix and $\otimes$ as a notation for Kronecker product.

Equation 9 can be written as follows.

$$
\boldsymbol{Y}=\boldsymbol{C Z}
$$

Equation 2 can be written as follows.

$$
\boldsymbol{Z}=\boldsymbol{W}+\boldsymbol{S}
$$

With $\boldsymbol{W}=\left(W_{1}, \ldots, W_{m n}\right)^{\prime} . E(Z \mid W)=W$ denoting that $W$ is the Minimum Mean Squared Error Linear Estimator (MMSELE) of $\boldsymbol{Z}$ with the term $\boldsymbol{W}$. Besides, equation 8 implies that $\sum_{S}=\sigma_{e}^{2} \boldsymbol{\Psi}_{S} \boldsymbol{\Psi}_{S}^{\prime}$. Therefore, Guerrero proposes that the value of the MMSELE from $Z$ with terms $W$ and $Y$ is as follows.

$$
\widehat{Z}=W+\widehat{A}(Y-C W)
$$

with $A$ as the disaggregation matrix with the following equation.

$$
\widehat{A}=\Psi_{S} \Psi_{S}^{\prime} C^{\prime}\left(C \Psi_{S} \Psi_{S}^{\prime} C^{\prime}\right)^{-1}
$$

In correcting the non-constant variance, the main diagonal matrix $\left(\boldsymbol{\Psi}_{s} \boldsymbol{\Psi}_{s}^{\prime}\right)$ is replaced by theoretical variance. The modified matrix is denoted by $\left(\boldsymbol{\Psi}_{\boldsymbol{s}} \boldsymbol{\Psi}_{\boldsymbol{s}}^{\prime}\right)_{m}$. 
The compatibility test aims to find out that $\left\{W_{t}\right\}$ is compatible (matching) with $\left\{Z_{t}\right\}$ or not. From the available series $\left\{W_{t}\right\}$, the following equations are determined:

$$
\boldsymbol{Y}-\boldsymbol{C} \boldsymbol{W}=\boldsymbol{C} \boldsymbol{\Psi}_{\boldsymbol{S}} \boldsymbol{e} \sim N\left(0, \sigma_{e}^{2} \boldsymbol{C} \boldsymbol{\Psi}_{S} \boldsymbol{\Psi}_{S}^{\prime} \boldsymbol{C}^{\prime}\right)
$$

The statistics compatibility test is as follows.

$$
K=\frac{(\boldsymbol{Y}-\boldsymbol{C} \boldsymbol{W})^{\prime}\left(\boldsymbol{C} \boldsymbol{\Psi}_{S} \boldsymbol{\Psi}_{S}^{\prime} \boldsymbol{C}^{\prime}\right)^{-1}(\boldsymbol{Y}-\boldsymbol{C} \boldsymbol{W})}{\widehat{\sigma}_{e}^{2}} \sim \chi_{(n)}^{2}
$$

Several studies on monthly GDP disaggregation have been conducted. The study, entitled "An Indicator of Monthly GDP and An Early Estimate of Quarterly GDP Growth" by Mitchell et al. (2005) is based on the fact that macroeconomic policy in the UK is faced with problems concerning the actual state of the economy. One of the variables used to generate monthly GDP is the manufacturing industry output. Meanwhile, one of the methods of temporal disaggregation was proposed by Guerrero in 2003 under the title "Monthly Disaggregation of a Quarterly Time Series and Forecast of Its Unobserved Monthly Values" study. In the study, quarterly GDP data of Mexico was disaggregated to obtain monthly GDP by using a combination of linear regression and time series ARIMA model analysis as well as some modifications. Another study was conducted by Moauro and Proietti in 2003 under the title "An Index of Coincident Indicators for the Euro Area based on Monthly and Quarterly Series." In that study, the monthly GDP value was obtained by using coincident indicators or indicators that have the same movement with the current economic condition. One of the coincident indicators used was industrial production which is reflected by the industrial production index value. The national monthly GDP of both the US and EU were compared in the study.

Based on the results of related research, it can be summarized that one of the goals of disaggregation of monthly GDP is to meet the needs of picturing the economic situation that occurred. There are several techniques in disaggregating, and one of them is the use of variables associated with applying linear regression model and time series model. The related variables can be coincident indicator one example of which is industrial production index.

\section{METHODOLOGY}

\subsection{Types and Sources of Data}

This study uses data obtained from the Central Bureau of Statistics (BPS) from 2000 through 2016. The first data is the quarterly Gross Domestic Product at constant prices (ADHK) in 2000 and 2010. The second data is the monthly production index of the Large and Medium Manufacturing Industry (IBS) of the reference year of 2000 and 2010. To simplify the naming, the production (IP) indices in question in the next section is the IBS production index.

The two data with different reference years are the same as the reference year of 2010 by using the comparison technique between the value of the year 2010 with the reference year of 2000 and the value of the year 2010 with the reference year of 2010. The forecasting will use production index data in January, February, and 
March. The results of forecasting will be compared with the value of GDP that has been released, i.e., the GDP of Quarter I and II of 2017.

\subsection{Definition of Time Observation Aggregate and Disaggregate}

The variable to be disaggregated in this research is GDP. These variables include the flow variable. That is, annual GDP is the sum of quarterly GDP so that quarterly GDP is also the sum of monthly GDP. In contrast, the annual GDP value may be distributed or distributed during the quarterly observation period. Thus, quarterly GDP allows being distributed (disaggregated) to monthly GDP. If the disaggregation process is done from quarterly GDP to monthly GDP, the disaggregated order $(m)$ is $m=3$ stating the number of months in each quarter the disaggregated vector is expressed as $c^{\prime}=\left(\frac{1}{m}, \frac{1}{m}, \frac{1}{m}\right)=\left(\frac{1}{3}, \frac{1}{3}, \frac{1}{3}\right)$. If the elements of the vector are summed, the result is expressed as the monthly averages of the quarter from now on referred to as the aggregate value. That is, the value has a monthly unit but is measured every three months/quarter. Meanwhile, a monthly value measured per month is called a disaggregated value. Thus, both aggregates and disaggregates have the same unit of value, i.e., monthly with different time observations, i.e., quarterly for aggregate and monthly for disaggregate. The variables used are GDP and production index (IP) the values of which will be calculated (aggregate and disaggregate values). The monthly GDP, that is the primary objective of calculation, can be named as disaggregated GDP. Meanwhile, the released GDP is still a quarterly value while the IP is a disaggregated value. Both series are converted into aggregate form. The GDP and aggregate IP can be calculated in the following way.

$$
\begin{aligned}
& Y_{i}=\frac{P D B_{i}}{3} \\
& I P A G R_{i}=\frac{I P_{3 i}+I P_{3 i-1}+I P_{3 i-2}}{3}
\end{aligned}
$$

With:

$Y_{i} \quad$ : average monthly GDP of quarterly or aggregate GDP of the quarter $\mathrm{i}^{\text {th }}$ (billion rupiahs)

$P D B_{i} \quad$ : Gross Domestic Product ADHK $2010 \mathrm{i}^{\text {th }}$ quarter (billion rupiahs)

$I P A G R_{i}$ : index of production (IP) aggregate $\mathrm{i}^{\text {th }}$

$I P_{t} \quad$ : index of production of Large and Medium Manufacturing Industry (IBS) base year $2010 \mathrm{t}^{\text {th }}$ month

i $\quad: 1,2, \ldots, 68(2000 /$ I until 2016/IV)

$t \quad: 1,2, \ldots . ., 204(2000 / 1$ until 2016/12).

\subsection{Monthly GDP disaggregation Procedure}

It is defined that the GDP of disaggregated or monthly/disaggregated GDP is the sum of the initial estimates of the monthly/disaggregated GDP and the disaggregate difference. Series preliminary monthly GDP estimate, from now on 
referred to as preliminary monthly estimate, is a proper value of a simple linear regression model with an independent variable which is the monthly production index (IP). The initial disaggregated estimation value is aggregated every three months, so it becomes the initial estimate of aggregate.

Meanwhile, the series that is known is the average monthly quarterly GDP or GDP aggregate. The difference between aggregate GDP and the initial aggregate estimate is called the aggregate difference. Furthermore, the aggregate difference will be distributed by using the disaggregation matrix (distribution) to obtain the disaggregate difference. Then, the disaggregate difference will be added to the initial monthly estimate so that monthly GDP can be generated.

The autocovariance relationship between the aggregate and disaggregated series, in which case the difference value will be identical (similar) to both series when the seasonal effect, is omitted (deseasonalization) ${ }^{14}$. Series, the seasonal effect of which that has been omitted, is called seasonally adjusted series. By utilizing an autocovariance relationship between seasonally adjusted series of aggregate and disaggregated differences, seasonally adjusted models of disaggregated disparity can be obtained. Then, the combination of aggregate difference model parameters and seasonally adjusted series model of disaggregate difference will form the disaggregated difference model. From the disaggregated difference model, the disaggregated matrix will be derived. The disaggregation matrix is a matrix that converts the value of the aggregate difference to the disaggregated difference value.

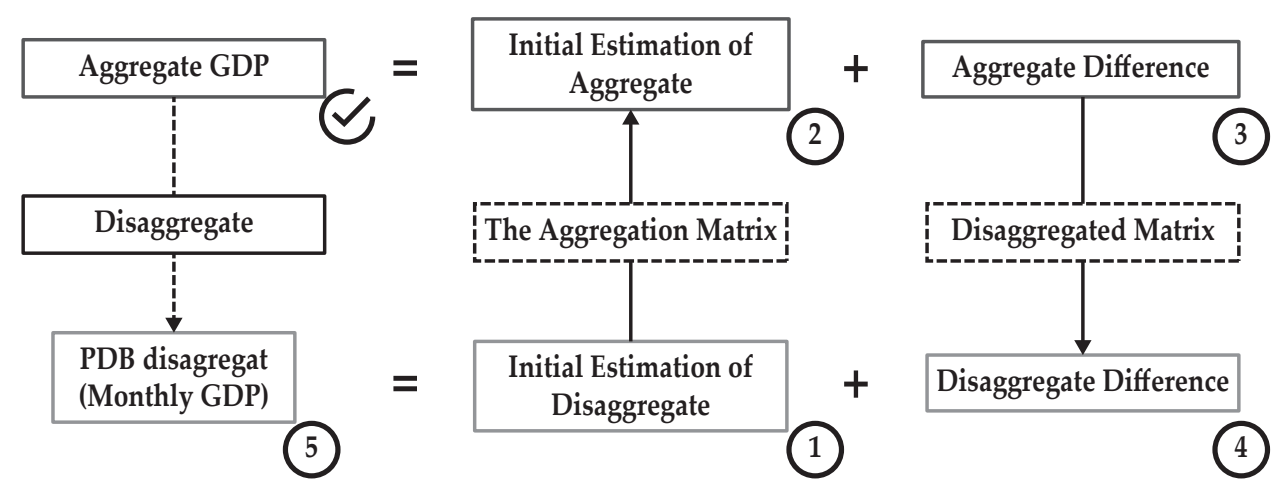

Figure 1.

The Quarterly GDP Disaggregation Stages in becoming Monthly GDP

\footnotetext{
${ }^{14}$ Wei, William W. S dan Stram, Daniel O. "Disaggregation of Time Series Models", Journal of the Royal Statistical Society, Series B (Methodology), Vol. 52, No. 3 (1990), 453-467, p. 466
} 
The above disaggregation equation can be expressed in the form of a matrix. Aggregate series has the following equation.

$$
\underset{68 \times 1}{(\boldsymbol{Y})}=\underset{68 \times 1}{(\boldsymbol{E})}+\underset{68 \times 1}{(\boldsymbol{D})}
$$

Series of disaggregated results or monthly GDP $(Z)$ can be expressed as follows.

$$
\underset{204 \times 1}{(\widehat{\boldsymbol{Z}})}=\underset{204 \times 1}{(\boldsymbol{W})}+\underset{204 \times 1}{(\boldsymbol{S})}
$$

(S)

The value of the disaggregate disparity $(S)$ can be further elaborated so that the monthly GDP equation is expressed as follows.

$$
\begin{aligned}
& \widehat{Z}=W+(\widehat{A} \times D) \\
& \widehat{Z}=W+[\widehat{A} \times(\boldsymbol{Y}-\boldsymbol{E})] \\
& \widehat{Z}=W+\widehat{A}[\boldsymbol{Y}-(\boldsymbol{C} \times \boldsymbol{W})]
\end{aligned}
$$

with:

$Y \quad$ : average monthly GDP of the quarter

E : initial estimation of aggregate

$D \quad$ : the aggregate difference

$\hat{W} \quad$ : monthly GDP

W : preliminary monthly estimates/disaggregate

$S \quad$ : disaggregate difference

$\hat{A} \quad$ : disaggregated matrix

C : the aggregation matrix

The aggregate initial estimation model is a simple linear regression model as follows.

$$
Y_{i}=\beta_{0}+\beta_{1} I P A G R_{i}+\varepsilon_{i}
$$

The monthly preliminary estimation model (disaggregate) is a model with the same parameters as the initial aggregate estimation model but with the independent variable converted to IP as follows.

$$
W_{t}=\widehat{\beta}_{0}+\widehat{\beta}_{1} I P_{t}
$$

The aggregate difference is assumed to follow the original seasonal ARMA model (pure seasonal) with the following equation.

$$
\Phi_{D}\left(L^{4}\right) D_{i}=\Theta_{D}\left(L^{4}\right) a_{i}
$$


The parameter estimation results from the model, used as the seasonal disaggregation difference model by replacing the following seasonal periods.

$$
\Phi_{S}\left(B^{12}\right) S_{t}=\Theta_{S}\left(B^{12}\right) e_{t}
$$

In addition to being a seasonally disaggregated difference model, the aggregate difference model is also used to compute the seasonally adjusted series of aggregate offsets or FDs in the following ways.

$$
F D_{i}=\Phi_{D}\left(L^{4}\right) \Theta_{D}\left(L^{4}\right)^{-1} D_{i}
$$

Meanwhile, a series of disaggregated disparities was eliminated as a seasonal effect (FS).

$$
F S_{t}=\Phi_{S}\left(B^{12}\right) \Theta_{S}\left(B^{12}\right)^{-1} S_{t}
$$

The seasonally adjusted series of the disaggregation difference model will be used as a non-seasonal disaggregation difference model with the following equation.

$$
\phi_{S}(B) F S_{t}=\theta_{S}(B) e_{t}
$$

Series disaggregate increments are assumed to follow the seasonal (multiplicative) ARMA model as follows.

$$
\phi_{S}(B) \Phi_{S}\left(B^{12}\right) S_{t}=\theta_{S}(B) \Theta_{S}\left(B^{12}\right) e_{t}
$$

\section{RESULTS AND DISCUSSION}

\subsection{The patterns of GDP and Production index (IP) movement}

In general, from Q1, the GDP always rose to the highest level in the Q3 with a slight decrease in the Q4. Furthermore, the increase occurred again in the first quarter of the following year with a value higher than the same quarter of the previous year so that overall, the GDP continues to move up. The pattern repeatedly occurs in each year, enabling the determination of a seasonal effect (Figure 2).

A coincident indicator of the economic circumstances that can be represented by GDP is the index of industrial production. It will move following the current state of the economy. This happens because the industrial sector has a strategic role, among other sectors, in generating added value (GDP). In conducting production activities, the industrial sector needs inputs from other sectors such as agriculture and mining so that it will increase the added value of the sector. Furthermore, the output of the industrial sector that has been generated will be used by many other sectors such as building, trade, hotel, transportation, and communications. That is, the industrial sector will boost the added value of the other sectors. In other words, all the added value generated, i.e., the value of GDP will move following the movement of the industrial sector. 
Based on the data, among the nine sectors/fields of business, the manufacturing sector contributes the most to the formation of the GDP in Indonesia. From 2012 to 2015 , the manufacturing industry has an average distribution of $21.31 \%{ }^{15}$. Also, the output value of Large and Medium Manufacturing Industry (IBS) always has a dominant contribution compared to the Micro and Small Manufacturing Industry (IMK). In 2015, the value of the IBS output amounted to 4,286,862 billion ${ }^{16}$. Meanwhile, IMK's output value amounted to $57,036.9$ billion $^{17}$. That is, the IBS output is dominant with $98.68 \%$ of the total industrial output, meaning that IBS is more representative than IMK.

The same pattern of movement between the GDP and the production index (IP) can be shown after both are converted into aggregate size or monthly averages of the quarter. In general, the GDP and IP move in tandem occupying the top position in the third quarter and dropping in the fourth quarter and rising again. The pattern repeats simultaneously every year so that the movement between the production index and GDP will be simultaneous or co-movement.

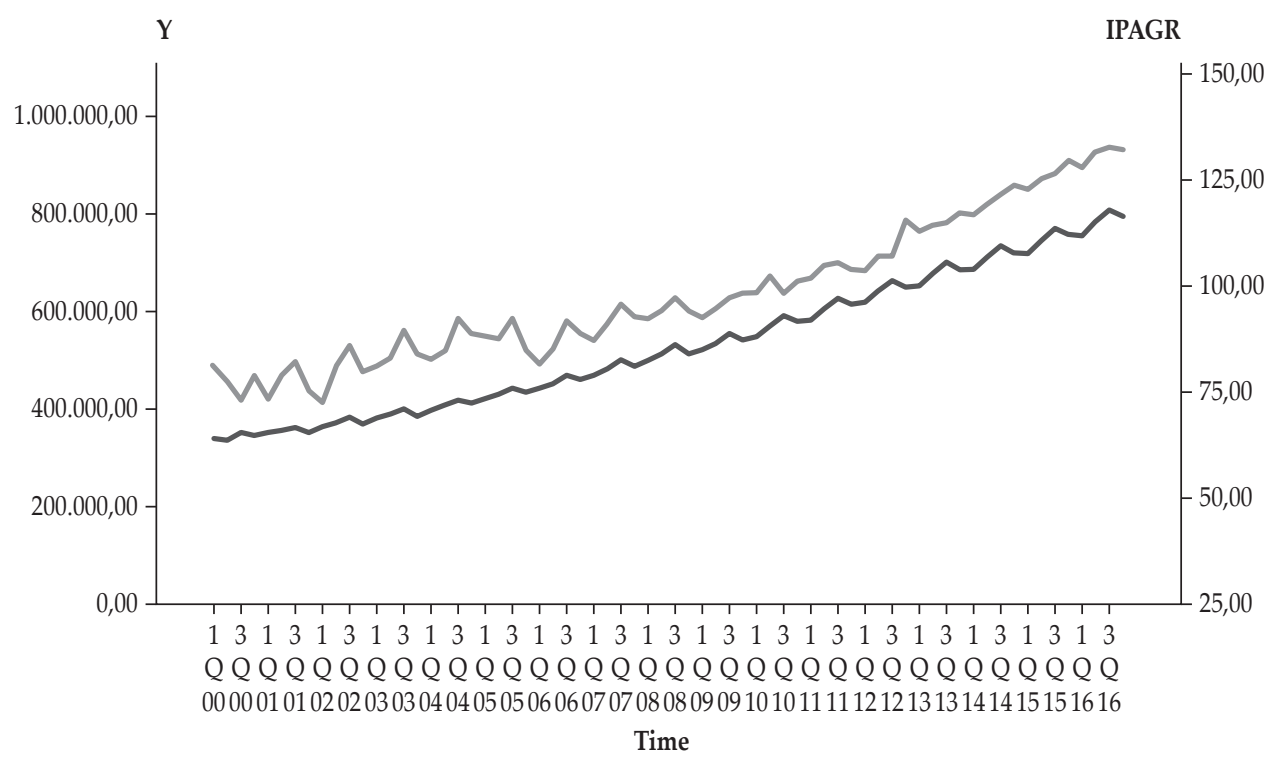

Source: BPS, processed

Figure 2. GDP Aggregate (Y) and Production Index Aggregate (IPAGR) of 2000-2016

${ }^{15}$ Central Bureau of Statistics, (2016), Indonesia Gross Domestic Product Quarterly 2012-2016, BPS, Jakarta.

${ }^{16}$ Central Bureau of Statistics. "Value of Large and Medium Manufacturing Outputs for 2012-2015"https://www.bps.go.id/linkTabelStatis/view/id/1081, 2017.

${ }^{17}$ Central Bureau of Statistics. "Value of Micro and Small Industry Output According to 2-digit KBLI year 2010-2015"https://www.bps.go.id/linkTableDinamis/view/id/1014, 2016. 


\subsection{Disaggregation of quarterly GDP into monthly GDP}

The first step is to form an aggregate of the initial estimation model in the form of a simple linear regression model with IPAGR as the independent variable and $Y$ as the dependent variable. From the model formed, the obtained statistical value (DW) is 1.05. This value leads to the conclusion that there is an autocorrelation problem that violates the standard assumption. Therefore, the autocorrelation problem is solved by the Cochrane-Orcutt variable transformation procedure. In that procedure, the $\hat{\rho}$ value is obtained by forming a regression model without intercepting with the independent variable which is the residual model $t^{\text {th }}-(t-1)$ and the dependent variable which is the t-residual. The $\hat{\rho}$ is the regression coefficient of the model. From the calculation results, the obtained $\hat{\rho}$ value is 0.448 .

Afterward, the $\hat{\rho}$ is used to perform the transformation of variables, i.e., $Y_{t}^{\prime}=Y_{t-0^{\prime}} 448 Y_{t-1}$ and IPAGR ${ }_{t}^{\prime}=I P A G R_{t-0} 448 I P A G R_{t-1}$. Then, the two transformed variables are remodeled. In returning to the real value, the intercept of the transformed model is changed to $\widehat{\beta}_{0}=\frac{\widehat{\beta}_{0}^{\prime}}{1-0,448}$.

Thus, the aggregate initial estimation model resulting from the transformation is as follows.

$$
\begin{gathered}
Y_{t}^{\prime}=E_{i}=-221434,57+7695,404 I P A G R_{t}^{\prime}, R^{2}=0,9068 \\
(16988,20) \quad(305,95)
\end{gathered}
$$

Description: numbers in brackets indicate standard error.

The transformation model has been freed from autocorrelation problems as indicated by DW statistics of 1.86 or near 2 . The p-values of the Jarque-Bera test and the Glejser test of the transformed model are 0.3011 and 0.1752 , respectively, leading to the assumptions that the normality and homoscedasticity requirements were met. The model shows a strong relationship between the two variables as evidenced by the large $R^{2}$. From the significance test of parameters, i.e., $t$-test and $F$ test, it is concluded that the IPAGR have the positive and significant effect towards Y.

Furthermore, the model is used as the initial monthly estimation model $\left(W_{t}\right)$ by substituting the independent variable with the following monthly IP.

$$
W_{t}=-221434,57+7695,404 I P_{t}
$$

The aggregated and disaggregated initial estimates are the fitted values of each model. Then, the values of the aggregate difference are calculated by subtracting the actual GDP (Y) from the initial estimate of aggregate (E). Then, the aggregate difference is modeled in the annual ARMA form. Based on the Box-Jenkins method, the aggregate difference model, that is ARMA $(1,0)_{{ }^{\prime}}$, can be obtained as follows.

$$
\left(1-0,6527 L^{4}\right) D_{i}=\hat{a}_{i}
$$

The result of the diagnostic test with Ljung-Box test shows that residual is white noise so that the model is ready to be used. The next stage is to form a model of disaggregate difference. 
The disaggregated difference model consists of seasonal and non-seasonal (multiplicative) models. The seasonal disaggregation difference model is formed from the aggregate difference model by substituting the previous 4 to 12 seasonal order. Based on equation 37, the seasonal disaggregation difference model is as follows.

$$
\left(1-0,6527 B^{12}\right) S_{t}=\hat{e}_{t}
$$

The non-seasonal disaggregation difference model is obtained based on the disaggregated difference model the seasonal effects of which have been omitted. The first step is to eliminate the seasonal effect (deseasonalization) on the series of aggregate differences. Series deseasonalization results are also called seasonally adjusted series. The value for seasonally adjusted series of aggregate differences was calculated based on the estimation of aggregate difference model parameters in equation 37 as follows.

$$
F D=D_{i}-0,6527 D_{i-4}
$$

Then, the defined seasonally adjusted series of aggregate (FD) and disaggregate (FS) relationships can be expressed in the form of backshift notation (B) as follows.

$$
F D_{i}=\frac{1}{3}\left(1+B+B^{2}\right) F S_{3 i}
$$

After the seasonally adjusted series of aggregate differences (FDs) were obtained, the series was used to determine the order of the seasonally adjusted series disaggregated (FS) difference model identified through the autocorrelation coefficient of FD. Based on autocorrelation plot (ACF) and partial autocorrelation (PACF), the indicated model was formed in the MA model so that the AR order value (p) is $p=0$. Then, the determination of MA order (q) is done based on Wei and Stram method ${ }^{18}$ For the order, MA (q), $q=p+1$ until $q=1$.

Based on equation 40 , the relationship between autocovariance lag 0 (variance) FD and autocovariance FS is expressed as follows.

$$
\begin{aligned}
& \gamma_{F D}(0)=\frac{1}{9}\left(1+B+B^{2}\right)^{2} \gamma_{F S}(2) \\
& =\frac{1}{9}\left[\gamma_{F S}(-2)+2 \gamma_{F S}(-1)+3 \gamma_{F S}(0)+2 \gamma_{F S}(1)+\gamma_{F S}(2)\right]
\end{aligned}
$$

Autocovariance relationship of first lag of FD and autocovariance FS is as follows.

$$
\begin{aligned}
& \gamma_{F D}(1)=\frac{1}{9}\left(1+B+B^{2}\right)^{2} \gamma_{F S}(5) \\
& =\frac{1}{9}\left[\gamma_{F S}(1)+2 \gamma_{F S}(2)+3 \gamma_{F S}(3)+2 \gamma_{F S}(4)+\gamma_{F S}(5)\right]
\end{aligned}
$$

${ }^{18}$ Wei, William W. S and Stram, Daniel O., op.cit., h. 461. 
Then, the MA model parameter is calculated. For $q=1$ or MA (1), the following assumption is used $\gamma_{F D}(k)=0$ for $k \neq 0, \pm 1$ and $\gamma_{F S}(k) \neq 0$ for $k=0, \pm 1$ in both equations (above) to obtain the following equation.

$$
\left[\begin{array}{l}
\gamma_{F D}(0) \\
\gamma_{F D}(1)
\end{array}\right]=\left[\begin{array}{cc}
3 / 9 & 4 / 9 \\
0 & 1 / 9
\end{array}\right] \times\left[\begin{array}{l}
\gamma_{F S}(0) \\
\gamma_{F S}(1)
\end{array}\right]
$$

By moving the segment, the autocovariance equation FS is as follows.

$$
\left[\begin{array}{l}
\gamma_{F S}(0) \\
\gamma_{F S}(1)
\end{array}\right]=\left[\begin{array}{cc}
3 & -12 \\
0 & 9
\end{array}\right] \times\left[\begin{array}{l}
\gamma_{F D}(0) \\
\gamma_{F D}(1)
\end{array}\right]
$$

Since the FD series is available, the autocovariance FD value can be determined so that the autocovariance value of FS can be calculated in the following way.

$$
\left[\begin{array}{l}
\hat{\gamma}_{F S}(0) \\
\hat{\gamma}_{F S}(1)
\end{array}\right]=\left[\begin{array}{cc}
3 & -12 \\
0 & 9
\end{array}\right] \times\left[\begin{array}{l}
479256955,6 \\
199066584,6
\end{array}\right]=\left[\begin{array}{c}
-951028147,8 \\
1791599261,05
\end{array}\right]
$$

From the autocovariance value, the lag one autocorrelation value is calculated in the following way.

$$
\hat{\rho}_{F S}(1)=\frac{\hat{\gamma}_{F S}(1)}{\hat{\gamma}_{F S}(0)}=-1,8
$$

However, the value is not significant because the range of the autocorrelation values is defined when $-1 \leq \rho \leq 1$ so that the MA model with the $q=1$ or MA (1) order is not possible. Then, the next level 1 order is selected, i.e., $q=2$ assuming that $\gamma_{F D}(k)=0$ for $\mathrm{k} \neq 0 \pm 1$ and $\gamma_{F S}(k) \neq 0$ for $k=0, \pm 2$. In the same way, the $\hat{\rho}_{F S}(2)=1.06$ is obtained so that MA (2) is also not possible. Next, $q=3$ is selected with the assumption that $\gamma_{F D}(k)=0$ for $k \neq 0, \pm 1$, and $\gamma_{F S}(k) \neq 0$ for $k=0, \pm 3$ to obtain $\hat{\rho}_{F S}(3)=0.415$. The autocorrelation value is significant so that the selected model is MA (3). In general, the MA equation (3) is as follows.

$$
F S_{t}=\left(1+\theta_{1} B+\theta_{2} B^{2}+\theta_{3} B^{3}\right) e_{t}
$$

Based on previous autocorrelation calculations, MA (1) and MA (2) are not possible so that the seasonally adjusted series disaggregated (FS) model for MA (3) is expressed as follows.

$$
F S_{t}=\left(1+\theta_{3} B^{3}\right) e_{t}
$$

The autocovariance value of FS obtained is then used to calculate the MA model parameter value. Without including $\theta_{1}$ and $\theta_{2}$ parameters, the MA (3) model for the FS has theoretical variance and autocovariance formulas which are $\gamma_{F S}(0)=\left(1+\theta_{3}^{2}\right) \sigma_{e}^{2}$ and $\gamma_{F S}(3)=\theta_{3} \sigma_{e}^{2}$. By substituting $\sigma_{e}^{2}=\frac{\gamma_{F S}(0)}{\left(1+\theta_{3}^{2}\right)}$ into the equation $\gamma_{F S}(3)$, the following equation is obtained. 
$\gamma_{F S}(3) \hat{\theta}_{3}^{2}-\gamma_{F S}(0) \hat{\theta}_{3}+\gamma_{F S}(3)=0$

Thus, the $\hat{\theta}_{3}$ value can be obtained by using the following formula ${ }^{17}$.

$$
\hat{\theta}_{(3) 1,2}=\frac{\left(\hat{\gamma}_{F S}(0) \pm \sqrt{\left[\hat{\gamma}_{F S}(0)\right]^{2}-4\left[\hat{\gamma}_{F S}(3)\right]^{2}}\right)}{2 \hat{\gamma}_{F S}(3)}
$$

From the calculations results, the following values were obtained $\hat{\theta}_{(3) 1}=0.533$ and $\hat{\theta}_{(3) 2}=1.873$. Like the MA model of order 1 , the model will be defined when $-1<\theta<1$, so the value of $\hat{\theta}_{3}$ that is possible is 0.533 . The seasonally adjusted series model of disaggregate differences can be written as follows.

$$
F S_{t}=\left(1+0,533 B^{3}\right) \hat{e}_{t}
$$

Because of the identic nature, the seasonally adjusted series model of disaggregate difference is used as a non-seasonal disaggregation model.

Thus, the disaggregated difference model is a multiplicative ARMA between the seasonal model of equation 38 and the non-seasonal model of equation 51 to form the following model.

$$
\left(1-0,6527 B^{12}\right) S_{t}=\left(1+0,533 B^{3}\right) \hat{e}_{t}
$$

With $\widehat{\sigma}_{e}^{2}=\hat{\gamma}_{F S}(3) / \widehat{\theta}_{3}=1119071291,11$.

Next, there is a balanced matrix $\left(\boldsymbol{\Psi}_{s}\right)$ consisting of pure MA parameter/weigh $(\psi)$ of the disaggregated difference model. The disaggregated model that is formed is $\left(1-\Phi B^{12}\right) S_{t}=\left(1+\theta B^{3}\right) \hat{e}_{t}$ so that the model needs to be converted into pure MA model form. The seasonal and non-seasonal (multiplicative) weighing values of the pure MA model is as follows.

$$
\psi_{q+12(j-1)}=\Phi^{j-1} \theta=(0,6527)^{j-1} \times 0,533 \text { for } j=1,2,3 \ldots
$$

Seasonal weights are as follows.

$$
\psi_{12 j}=\Phi^{j}=(0,6527)^{j} \text { for } j=0,1,2 \ldots
$$

While $\psi_{j}=0$ for other $j$. The weighting matrix is a lower triangular matrix with value one as the main diagonal, $\psi_{1}$ as the first sub-diagonal, $\psi_{2}$ as the second sub-diagonal. In overcoming the variance which is not constant, the main diagonal of the matrix $\Psi_{s} \Psi_{s}^{\prime}$ is modified by the theoretical variance, i.e., $\operatorname{Var}\left(S_{t}\right) / \hat{\sigma}_{e}^{2}=\left(1+\theta^{2}\right) /\left(1-\Phi^{2}\right)$. After the balanced matrix is obtained, the disaggregated matrix is calculated according to equation 16.

${ }^{17}$ Box, George E. P., Jenkins, Gwilym M., and Reinsel, Gregory C, (2008), Time Series Analysis: Forecasting and Control ( $4^{\text {th }}$ ed $)$, John Wiley \& Sons, Inc, New Jersey. 
Furthermore, the disaggregation matrix is multiplied by the series of aggregate differences to obtain the disaggregated difference series. Between the monthly preliminary estimate series and the disaggregate gap is summed to obtain monthly GDP. Monthly GDP of disaggregated results along with initial estimation values can be seen in the following figure.

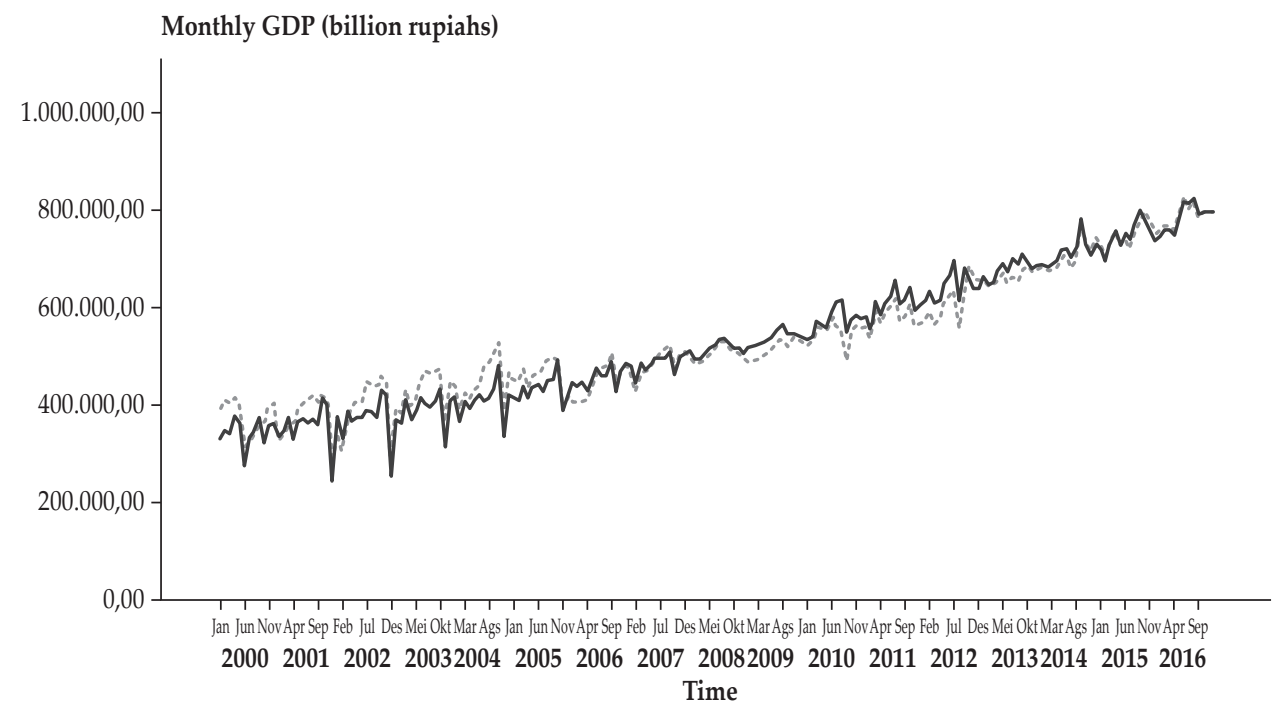

Source: processing results

Figure 3. Disaggregated Results of Monthly GDP and Initial Estimates of 2000/1-2016/12

From the figure, it can be seen that the monthly GDP fluctuates with an increasing trend. If the quarterly pattern is observed, the GDP changes (variation) for example up and down or vice versa. The monthly GDP figures of complete disaggregation results can be seen in the appendix.

Series between preliminary GDP estimates and disaggregated GDP appear to have the same or compatible movement. In ensuring the similarity of the two series, a compatibility test is performed. The results of the compatibility test yield statistical test of $K=61.89$. The value is smaller than the table value of $\chi^{2}$ with 68 degrees of freedom (quarterly amount) resulting in the decision that the monthly GDP series of disaggregated $\hat{Z}$ and initial monthly (W) estimates are similar or compatible. Thus, it can be deduced that there is a standard motion between actual GDP and initial estimates (compatible). These conclusions imply that the disaggregation and forecasting of monthly GDP can be done with a production index that acts as a coincident indicator.

\subsection{Quarterly and Monthly GDP Forecasts in 2017}

To determine the GDP growth in 2017, the forecasting with ARIMA model based on initial monthly estimation series of the GDP (from now on referred to as 
monthly GDP estimation results). In order to have a better model, a comparison is needed between the model estimated monthly GDP without entering the latest IP data (Model A) and monthly GDP estimates by entering the latest IP data (Model B). To estimate the results can be added and compared with the original quarterly GDP data, the amount of the latest IP data was used in 3 data from January to March 2017 with the value of each as follows: 131.05; 133,43; and 135.79. Based on the model estimation, the accuracy level of model A and B in the data in the sample is as follows.

Table 2.

Comparison of Accuracy between Model A and Model B (data in a sample)

\begin{tabular}{lcc}
\hline \multicolumn{1}{c}{ Comparison } & Model A & Model B \\
\hline \multicolumn{1}{c}{$(1)$} & $(2)$ & $(3)$ \\
RMSE (Billion) & $31.849,12$ & $31.700,87$ \\
MAPE (\%) & 4.50 & 4.46 \\
MPE (\%) & -0.52 & -0.52 \\
\hline
\end{tabular}

Source : Processed results

The value of the three criteria shows a corresponding result that Model B has a smaller criterion value than Model A. The smaller the value, the more accurate the model for forecasting. Thus, Model B is a better model for forecasting and is also an ARIMA model $(1,0,1)(2,1,0)_{12}$ with the following equation.

$$
\begin{gathered}
(1-0,8315 B)\left(1+0,2503 B^{12}+0,3113 B^{24}\right)\left(1-B^{12}\right) W_{t^{-}} 17 \\
=2122,0106+(1-0,5009 B) U_{t-} 17
\end{gathered}
$$

With $W_{t-17}$ as a notation for monthly GDP estimation results by entering the latest IP data.

In addition to the model selection criteria, the determination of Model B as a more appropriate model for forecasting can be done by comparing the value of forecasting results summed every three months with the actual value of the GDP in the first and second quarters of 2017. Model B provides the result of forecasting which is closer to the actual value of the GDP. 
Table 3.

Forecasting of Model A and B in The First and Second Quarters of 2017 (billion rupiahs)

\begin{tabular}{|c|c|c|c|}
\hline Periods & $\begin{array}{l}\text { Quarterly GDP } \\
\text { (actual data) }\end{array}$ & $\begin{array}{l}\text { Forecasting with Model } \\
\text { A }\end{array}$ & $\begin{array}{l}\text { Forecasting with Model } \\
\text { B }\end{array}$ \\
\hline (1) & (2) & (3) & (4) \\
\hline January & & $781,391.80$ & $781,725.20$ \\
\hline February & $2,377,574.70$ & $791,144.90$ & $793,253.70$ \\
\hline March & & $788,193.60$ & $794,235.40$ \\
\hline Total & $2,377,574.70$ & $2,360,730.30$ & $2,369,214.30$ \\
\hline \multicolumn{2}{|c|}{ Difference } & $16,844.40$ & $8,360.40$ \\
\hline April & & $779,160.50$ & $794,070.10$ \\
\hline May & $2,472,771.50$ & $812,620.00$ & $824,995.50$ \\
\hline June & & $836,896.90$ & $847,387.20$ \\
\hline Total & $2,472,771.50$ & $2,428,677.40$ & $2,466,452.80$ \\
\hline \multicolumn{2}{|c|}{ Difference } & $44,094.10$ & $6,318.70$ \\
\hline \multicolumn{2}{|c|}{ RMSE } & $33,376.81$ & $7,410.20$ \\
\hline
\end{tabular}

Source : processing results

Also, when viewed from the value of forecasting accuracy on quarterly data, model B was proved to be a better model for forecasting due to the high accuracy shown by smaller MAPE and MPE values.

Table 4.

Comparison of Forecasting Accuracy of Model A and B on Quarterly Data

\begin{tabular}{lccrr}
\hline & Periods & \multicolumn{3}{c}{ MAPE (\%) } \\
\cline { 2 - 5 } & \multicolumn{1}{c}{ Model A } & \multicolumn{3}{c}{ Model B } \\
\hline & -2 & & -3 & 0,35 \\
Quarter I & & $0,71^{*}$ & $0,26^{*}$ \\
Quarter II & & $1,78^{*}$ & & 0,30 \\
Quarters I and II & & 1,25 & \\
\hline Source Processed results
\end{tabular}

Source : Processed results
Description : the "**" mark= value is calculated based on data out the sample.

The MPE value is not listed because the value is the same as MAPE.

If summed up to the quarterly values, the forecasting results remain consistent with the general pattern of the GDP movement that reached the highest value in the third quarter as shown in the figure below. 


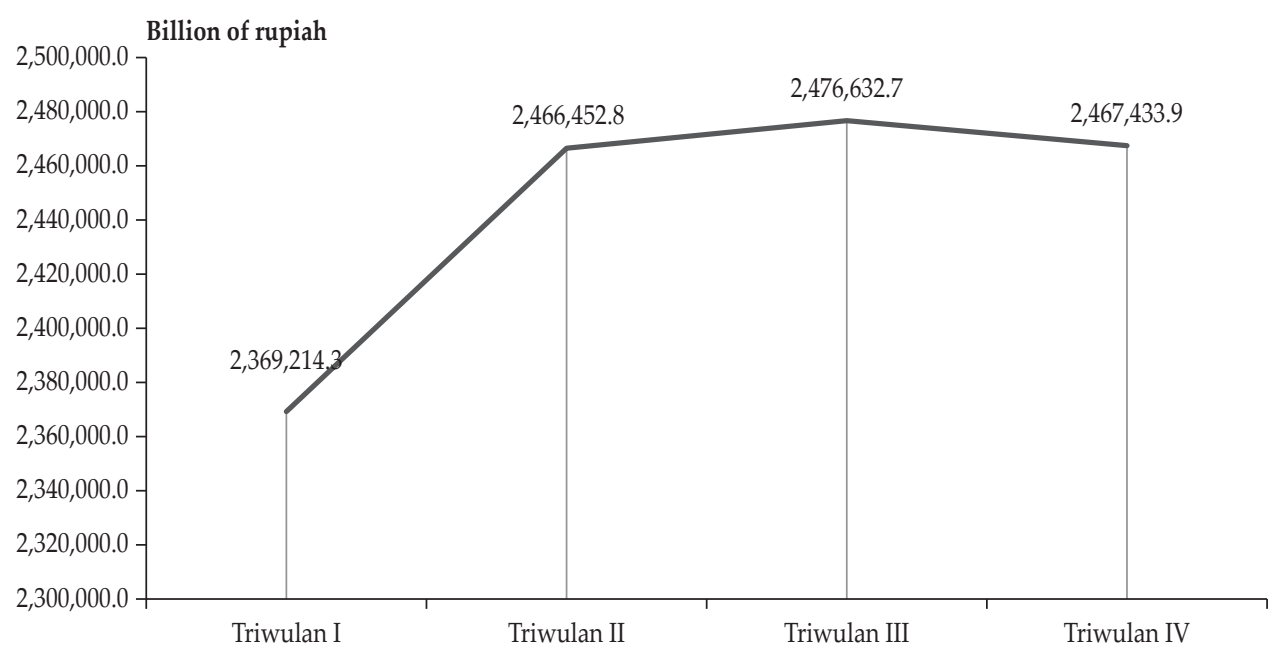

Source: Processed results

Figure 4. Results of Indonesia's Quarterly GDP Forecasting in 2017 (billion rupiahs)

Although the highest quarterly GDP was in quarter III, the highest monthly GDP occurred in June (second quarter). This is possible because the month coincided with both school and Ramadam holidays so that some business fields experience a surge in demand. Those business fields are Manufacturing Industry, Trade, Hotel and Restaurant, and Transportation and Communication.

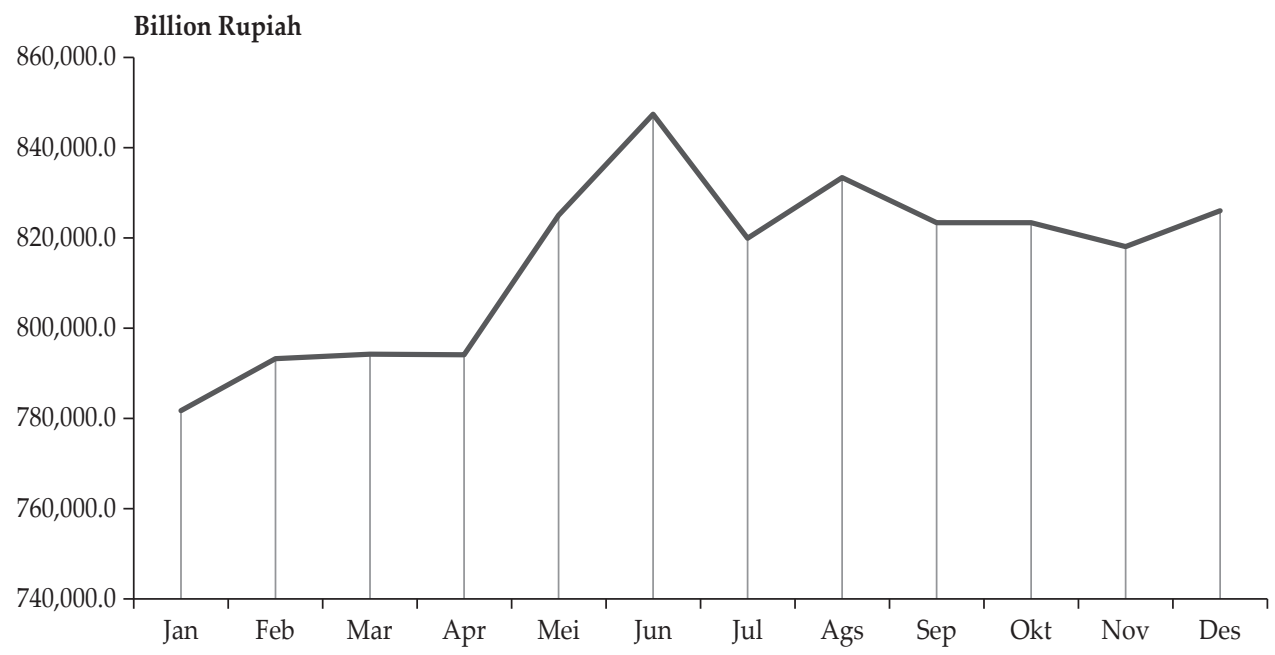

Figure 5. Indonesia's Monthly GDP Forecasts for 2017 (billion rupiahs) 
Besides, the monthly GDP movements vary from month to quarter. Monthly GDP in the first quarter, III, IV change in a fluctuating way, i.e., up and down or vice versa. In contrast to the other quarter, monthly GDP in the second quarter in a row continues to increase. Also, it appears that the economic activity increased gradually in the first half to reach the peak position in June 2017. For the next semester of July to December 2017, the economic situation is predicted to run stable.

\section{CONCLUSION}

Several conclusions are made from the results and discussion. First, the disaggregation results indicate that the monthly GDP volatilely moves with different patterns between nations. Second, the disaggregation and monthly GDP forecasting can be proven by the production index of Large and Medium Manufacturing Industry (IBS) which acts as a coincident indicator. Third, the result of GDP forecasting in 2017 shows that the highest quarterly GDP remains consistent in the third quarter. However, the highest monthly GDP occurred in June (second quarter). The pattern of quarterly GDP movement is not always in line with the pattern of monthly movement. The monetary policy formulated through empirical studies, linking it to GDP variables, can be miss-leading if the quarterly GDP aggregate is used.

Based on the above conclusions, some suggestions may be submitted. In fact, policymakers are wary of fluctuating economic growth from month to month. Therefore, further analysis of the monthly GDP has been made. Also, the results of monthly disaggregated GDP can be explored with other monthly economic variables, especially financial variables so that the economic state analysis becomes comprehensive. Furthermore, in enacting policy, the government must pay attention to the peak of the economic activities. Although the highest GDP was in a particular quarter, the highest monthly GDP was unlikely to occur during the quarter.

For general data users, disaggregation and forecasting of monthly GDP can be done using the Large and Medium Manufacturing Industry Production Index (IBS) that acts as a coincident indicator. Data users need to monitor the development of the production index in anticipation of the resulting estimate being improper. For more accurate forecasting, the model needs to be updated on a regular basis based on the latest production index data. Related to further research, we can use some method of disaggregation so that an inter-method comparison can be made. 


\section{REFERENCES}

Badan Pusat Statistik. (2016a). Produk Domestik Bruto Indonesia Triwulanan 2012-2016, BPS, Jakarta.

Badan Pusat Statistik. (2016b). Nilai Output Industri Mikro dan Kecil Menurut 2-digit KBLI tahun 2010-2015" https://www.bps.go.id/linkTableDinamis/view/ id/ 1014

Badan Pusat Statistik.. (2017). Nilai Output Industri Besar dan Sedang tahun 20122015" https://www.bps.go.id/linkTabelStatis/view/id/1081

Bank Indonesia. (2017). Jadwal Rapat Dewan Gubernur (RDG) http://www.bi.go. id/id/ruang-media/agenda/rapat-dewan-gubernur/Default.aspx, 2017.

Box, George E. P., Jenkins, Gwilym M., dan Reinsel, Gregory C. (2008). Time Series Analysis: Forecasting and Control ( $\left.4^{\text {th }} \mathrm{ed}\right)$. New Jersey: John Wiley \& Sons, Inc.

Bruno et al. (2005). Short-run GDP Forecasting in G7 Countries: Temporal Disaggregation Techniques and Bridge Models. Europan Communities Working Paper Studies, Juli 2005.

Guerro, M. Victor. (2003). Monthly Disaggregation of a Quarterly Time Series and Forecast of Its Unobservable Monthly Values. Journal of Official Statistics, Vol. 19, No. 3, 215-235.

Katz, Mithcell H. (2006). Multivariable Analysis: A Practical Guide for Clinicians.. Cambridge: Cambridge University Press.

Mankiw, N. Gregory. (2011). Macroeconomics (7 $7^{\text {th }}$ ed). New York: Worth Publishers.

Mitchell et al. (2005). An Indicator of Monthly GDP and An Early Estimate of Quarterly GDP Growth. The Economic Journal, Februari 2005, F108-F129.

Moauro, Filippo dan Proietti, Tommaso. (2003). An index of Coincident Indicators for the Euro Area based on Monthly and Quaterly Time Series. Europan Communities Working Paper Studies, Oktober 2003.

Mongardini, Joannes dan Saadi-sedik, Tahsin. (2003). Estimating Indexes of Coincident and Leading Indicator: An Application of Jordan. IMF Working Paper, Agustus 2003.

Rianto dan Hendranata, Anton. (2014). Updating Leading Indicators Perekonomian Indonesia. Laporan akhir oleh Kementerian Keuangan Republik Indonesia Badan Kebijakan Fiskal Pusat Kebijakan Ekonomi Makro.

Sax, Christop dan Steiner, Peter. (2013). Temporal Disaggregation of Time Series. The R Journal, Desember 2013, 80-87.

Sutomo. (2016). Sistem Data dan Perangkat Analisis Ekonomi Makro. Bandung: CorBooks.

Wei, William W. S dan Stram, Daniel O. (1990). Disaggregation of Time Series Models. Journal of the Royal Statistical Society, Series B (Methodology), Vol. 52, No. 3, 453-467. 


\section{APPENDIXES}

Appendix 1. Data with 68 observations

\begin{tabular}{|c|c|c|c|c|c|c|}
\hline Year & Quarter & GDP & $Y$ & IPAGR & $E$ & $\mathrm{D}$ \\
\hline-1 & -2 & -3 & -4 & -5 & -6 & -7 \\
\hline \multirow{4}{*}{2000} & I & 1016818,5 & 338939,50 & 81,02 & 402021,48 & $-63081,98$ \\
\hline & II & 1010924,9 & 336974,97 & 77,62 & 375908,41 & $-38933,44$ \\
\hline & III & 1053704,0 & 351234,67 & 73,22 & 341997,32 & 9237,34 \\
\hline & IV & 1040278,9 & 346759,63 & 79,03 & 386758,93 & $-39999,30$ \\
\hline \multirow{4}{*}{2001} & I & 1056151,9 & 352050,63 & 73,22 & 341997,32 & 10053,31 \\
\hline & II & 1069254,9 & 356418,30 & 79,03 & 386758,93 & $-30340,63$ \\
\hline & III & 1089969,0 & 363323,00 & 82,29 & 411845,95 & $-48522,95$ \\
\hline & IV & 1056524,1 & 352174,70 & 75,38 & 358619,40 & $-6444,70$ \\
\hline \multirow{4}{*}{2002} & I & 1093329,2 & 364443,07 & 72,57 & 337020,96 & 27422,10 \\
\hline & II & 1114298,6 & 371432,87 & 81,48 & 405612,67 & $-34179,81$ \\
\hline & III & 1150477,1 & 383492,37 & 86,20 & 441883,68 & $-58391,31$ \\
\hline & IV & 1106008,1 & 368669,37 & 79,79 & 392556,14 & $-23886,77$ \\
\hline \multirow{4}{*}{2003} & I & 1146990,2 & 382330,07 & 81,14 & 402996,23 & $-20666,17$ \\
\hline & II & 1170350,3 & 390116,77 & 82,94 & 416796,66 & $-26679,89$ \\
\hline & III & 1202935,5 & 400978,50 & 89,56 & 467791,54 & $-66813,04$ \\
\hline & IV & 1157238,1 & 385746,03 & 83,88 & 424030,34 & $-38284,31$ \\
\hline \multirow{4}{*}{2004} & I & 1194007,6 & 398002,53 & 82,87 & 416257,98 & $-18255,45$ \\
\hline & II & 1221702,5 & 407234,17 & 84,52 & 428981,05 & $-21746,89$ \\
\hline & III & 1257044,9 & 419014,97 & 92,51 & 490492,99 & $-71478,02$ \\
\hline & IV & 1240079,0 & 413359,67 & 88,84 & 462250,85 & $-48891,19$ \\
\hline \multirow{4}{*}{2005} & I & 1265229,8 & 421743,27 & 88,25 & 457659,26 & $-35915,99$ \\
\hline & II & 1293431,8 & 431143,93 & 87,74 & 453760,26 & $-22616,32$ \\
\hline & III & 1330433,8 & 443477,93 & 92,42 & 489749,10 & $-46271,17$ \\
\hline & IV & 1303405,1 & 434468,37 & 84,84 & 431469,23 & 2999,13 \\
\hline \multirow{4}{*}{2006} & I & 1330100,5 & 443366,83 & 81,45 & 405330,51 & 38036,33 \\
\hline & II & 1357241,7 & 452413,90 & 85,26 & 434650,00 & 17763,90 \\
\hline & III & 1408450,6 & 469483,53 & 92,05 & 486927,45 & $-17443,92$ \\
\hline & IV & 1382344,8 & 460781,60 & 88,75 & 461506,96 & $-725,36$ \\
\hline \multirow{4}{*}{2007} & I & 1410639,9 & 470213,30 & 87,28 & 450194,72 & 20018,58 \\
\hline & II & 1448540,6 & 482846,87 & 91,15 & 480001,59 & 2845,28 \\
\hline & III & 1503442,4 & 501147,47 & 95,75 & 515374,80 & $-14227,33$ \\
\hline & IV & 1463103,6 & 487701,20 & 92,70 & 491955,12 & $-4253,92$ \\
\hline \multirow{4}{*}{2008} & I & 1498358,5 & 499452,83 & 92,38 & 489492,59 & 9960,25 \\
\hline & II & 1539837,1 & 513279,03 & 94,16 & 503164,76 & 10114,28 \\
\hline & III & 1597480,8 & 532493,60 & 97,28 & 527148,77 & 5344,83 \\
\hline & IV & 1540392,0 & 513464,00 & 94,10 & 502703,03 & 10760,97 \\
\hline
\end{tabular}


Data with 68 observations (continued)

\begin{tabular}{|c|c|c|c|c|c|c|}
\hline Year & Quarter & PDB & $\mathbf{Y}$ & IPAGR & E & D \\
\hline 1 & (2) & (3) & (4) & (5) & (6) & (7) \\
\hline \multirow{4}{*}{2009} & I & 1566089,7 & 522029,90 & 92,55 & 490800,81 & 31229,09 \\
\hline & II & 1603521,5 & 534507,17 & 94,76 & 507782,00 & 26725,17 \\
\hline & III & 1665681,5 & 555227,17 & 97,36 & 527815,70 & 27411,46 \\
\hline & IV & 1626658,3 & 542219,43 & 98,30 & 534998,08 & 7221,35 \\
\hline \multirow{4}{*}{2010} & I & 1642356,3 & 547452,10 & 98,41 & 535895,88 & 11556,22 \\
\hline & II & 1709132,0 & 569710,67 & 102,35 & 566215,77 & 3494,89 \\
\hline & III & 1775109,9 & 591703,30 & 98,12 & 533664,21 & 58039,09 \\
\hline & IV & 1737534,9 & 579178,30 & 101,11 & 556622,17 & 22556,13 \\
\hline \multirow{4}{*}{2011} & I & 1748731,2 & 582910,40 & 101,86 & 562419,37 & 20491,03 \\
\hline & II & 1816268,2 & 605422,73 & 105,02 & 586711,20 & 18711,53 \\
\hline & III & 1881849,7 & 627283,23 & 105,56 & 590866,72 & 36416,51 \\
\hline & IV & 1840786,2 & 613595,40 & 103,94 & 578451,47 & 35143,93 \\
\hline \multirow{4}{*}{2012} & I & 1855580,2 & 618526,73 & 103,62 & 575937,64 & 42589,10 \\
\hline & II & 1929018,7 & 643006,23 & 107,16 & 603205,02 & 39801,21 \\
\hline & III & 1993632,3 & 664544,10 & 107,27 & 604025,86 & 60518,24 \\
\hline & IV & 1948852,2 & 649617,40 & 115,47 & 667179,49 & $-17562,09$ \\
\hline \multirow{4}{*}{2013} & I & 1958395,5 & 652798,50 & 112,93 & 647633,16 & 5165,34 \\
\hline & II & 2036816,6 & 678938,87 & 114,41 & 659022,36 & 19916,51 \\
\hline & III & 2103598,1 & 701199,37 & 115,00 & 663562,65 & 37636,72 \\
\hline & IV & 2057687,6 & 685895,87 & 117,20 & 680492,54 & 5403,33 \\
\hline \multirow{4}{*}{2014} & I & 2058584,9 & 686194,97 & 116,91 & 678209,57 & 7985,40 \\
\hline & II & 2137385,6 & 712461,87 & 119,21 & 695934,65 & 16527,22 \\
\hline & III & 2207343,6 & 735781,20 & 121,64 & 714634,48 & 21146,72 \\
\hline & IV & 2161552,5 & 720517,50 & 123,68 & 730333,11 & $-9815,61$ \\
\hline \multirow{4}{*}{2015} & I & 2157848 & 719282,67 & 122,82 & 723715,06 & $-4432,39$ \\
\hline & II & 2238761,7 & 746253,90 & 125,47 & 744082,23 & 2171,67 \\
\hline & III & 2312640 & 770880,00 & 126,51 & 752111,11 & 18768,89 \\
\hline & IV & 2273261,6 & 757753,87 & 129,56 & 775582,09 & $-17828,22$ \\
\hline \multirow{4}{*}{2016} & I & 2264089,7 & 754696,57 & 127,89 & 762730,76 & $-8034,20$ \\
\hline & II & 2354797,7 & 784932,57 & 131,76 & 792486,33 & $-7553,76$ \\
\hline & III & 2428569,9 & 809523,30 & 132,67 & 799540,45 & 9982,85 \\
\hline & IV & 2385577,1 & 795192,37 & 132,26 & 796385,34 & $-1192,97$ \\
\hline
\end{tabular}


Appendix 2. Data with 204 observations

\begin{tabular}{|c|c|c|c|c|c|c|c|c|}
\hline Month & Year & IP & $\begin{array}{c}\text { Initial } \\
\text { Estimations } \\
(W)\end{array}$ & $\begin{array}{l}\text { Monthly } \\
\text { GDP (Z) }\end{array}$ & Year & IP & $\begin{array}{c}\text { Initial } \\
\text { Estimation } \\
(W)\end{array}$ & $\begin{array}{l}\text { Monthly } \\
\text { GDP (Z) }\end{array}$ \\
\hline$(1)$ & (2) & (3) & (4) & (5) & (6) & (7) & (8) & (9) \\
\hline 1 & \multirow{12}{*}{2000} & 79,73 & 392120,06 & 329038,08 & \multirow{12}{*}{2001} & 71,04 & 325246,99 & 335300,30 \\
\hline 2 & & 82,03 & 409819,49 & 346737,51 & & 72,47 & 336251,42 & 346304,73 \\
\hline 3 & & 81,29 & 404124,89 & 341042,91 & & 76,14 & 364493,56 & 374546,87 \\
\hline 4 & & 82,57 & 413975,01 & 375041,57 & & 75,51 & 359645,45 & 329304,82 \\
\hline 5 & & 81,02 & 402047,13 & 363113,69 & & 80,49 & 397968,57 & 367627,94 \\
\hline 6 & & 69,28 & 311703,08 & 272769,64 & & 81,1 & 402662,77 & 372322,14 \\
\hline 7 & & 71,04 & 325246,99 & 334484,34 & & 82,13 & 410589,03 & 362066,08 \\
\hline 8 & & 72,47 & 336251,42 & 345488,76 & & 83,33 & 419823,52 & 371300,57 \\
\hline 9 & & 76,14 & 364493,56 & 373730,90 & & 81,42 & 405125,30 & 356602,35 \\
\hline 10 & & 75,51 & 359645,45 & 319646,16 & & 83,87 & 423979,04 & 417534,34 \\
\hline 11 & & 80,49 & 397968,57 & 357969,27 & & 81,13 & 402893,63 & 396448,93 \\
\hline 12 & & 81,1 & 402662,77 & 362663,47 & & 61,13 & 248985,53 & 242540,83 \\
\hline 1 & \multirow{12}{*}{2002} & 74,05 & 348410,16 & 375832,27 & \multirow{12}{*}{2003} & 79,71 & 391966,15 & 371299,99 \\
\hline 2 & & 68,05 & 302237,73 & 329659,84 & & 78,63 & 383655,12 & 362988,95 \\
\hline 3 & & 75,61 & 360414,99 & 387837,10 & & 85,09 & 433367,43 & 412701,26 \\
\hline 4 & & 80,81 & 400431,10 & 366251,29 & & 80,10 & 394967,36 & 368287,47 \\
\hline 5 & & 81,91 & 408896,05 & 374716,24 & & 82,23 & 411358,57 & 384678,68 \\
\hline 6 & & 81,73 & 407510,87 & 373331,07 & & 86,48 & 444064,05 & 417384,15 \\
\hline 7 & & 86,8 & 446526,58 & 388135,26 & & 89,51 & 467381,12 & 400568,08 \\
\hline 8 & & 86,51 & 444294,91 & 385903,59 & & 88,86 & 462379,11 & 395566,07 \\
\hline 9 & & 85,28 & 434829,56 & 376438,25 & & 90,32 & 473614,40 & 406801,36 \\
\hline 10 & & 88,02 & 455914,97 & 432028,20 & & 90,15 & 472306,18 & 434021,87 \\
\hline 11 & & 86,38 & 443294,51 & 419407,74 & & 74,60 & 352642,63 & 314358,33 \\
\hline 12 & & 64,96 & 278458,93 & 254572,16 & & 86,88 & 447142,21 & 408857,90 \\
\hline 1 & \multirow{12}{*}{2004} & 85,65 & 437676,86 & 419421,41 & \multirow{12}{*}{2005} & 87,37 & 450912,96 & 414996,96 \\
\hline 2 & & 78,49 & 382577,76 & 364322,31 & & 86,83 & 446757,44 & 410841,44 \\
\hline 3 & & 84,46 & 428519,33 & 410263,88 & & 90,54 & 475307,39 & 439391,40 \\
\hline 4 & & 82,37 & 412435,93 & 390689,05 & & 85,27 & 434752,61 & 412136,28 \\
\hline 5 & & 84,80 & 431135,77 & 409388,88 & & 88,79 & 461840,43 & 439224,11 \\
\hline 6 & & 86,39 & 443371,46 & 421624,57 & & 89,16 & 464687,73 & 442071,41 \\
\hline 7 & & 91,08 & 479462,91 & 407984,89 & & 90,34 & 473768,31 & 427497,14 \\
\hline 8 & & 91,89 & 485696,19 & 414218,16 & & 93,42 & 497470,16 & 451198,99 \\
\hline 9 & & 94,57 & 506319,87 & 434841,85 & & 93,49 & 498008,83 & 451737,67 \\
\hline 10 & & 98,00 & 532715,11 & 483823,92 & & 92,70 & 491929,46 & 494928,60 \\
\hline 11 & & 78,76 & 384655,52 & 335764,33 & & 78,88 & 385578,97 & 388578,10 \\
\hline 12 & & 89,77 & 469381,93 & 420490,74 & & 82,95 & 416899,27 & 419898,40 \\
\hline
\end{tabular}




\section{Data with 68 observations (continued)}

\begin{tabular}{|c|c|c|c|c|c|c|c|c|}
\hline Month & Year & IP & $\begin{array}{c}\text { Initial } \\
\text { Estimation } \\
\text { (W) }\end{array}$ & $\begin{array}{l}\text { Monthly } \\
\text { GDP (Z) }\end{array}$ & Year & IP & $\begin{array}{l}\text { Initial } \\
\text { Estimation } \\
\text { (W) }\end{array}$ & $\begin{array}{l}\text { Monthly } \\
\text { GDP (Z) }\end{array}$ \\
\hline$(1)$ & $(2)$ & (3) & (4) & (5) & (6) & $(7)$ & (8) & (9) \\
\hline 1 & \multirow{12}{*}{2006} & 81,65 & 406895,24 & 444931,57 & \multirow{12}{*}{2007} & 88,65 & 460763,07 & 480781,66 \\
\hline 2 & & 80,81 & 400431,10 & 438467,43 & & 83,69 & 422593,87 & 442612,45 \\
\hline 3 & & 81,88 & 408665,18 & 446701,51 & & 89,49 & 467227,21 & 487245,80 \\
\hline 4 & & 82,01 & 409665,59 & 427429,49 & & 89,59 & 467996,76 & 470842,03 \\
\hline 5 & & 85,25 & 434598,70 & 452362,60 & & 90,87 & 477846,87 & 480692,15 \\
\hline 6 & & 88,51 & 459685,72 & 477449,62 & & 92,99 & 494161,13 & 497006,41 \\
\hline 7 & & 90,67 & 476307,79 & 458863,87 & & 94,97 & 509398,03 & 495170,70 \\
\hline 8 & & 90,72 & 476692,56 & 459248,64 & & 95,21 & 511244,93 & 497017,60 \\
\hline 9 & & 94,76 & 507782,00 & 490338,08 & & 97,06 & 525481,43 & 511254,10 \\
\hline 10 & & 84,27 & 427057,20 & 426331,84 & & 89,00 & 463456,47 & 459202,55 \\
\hline 11 & & 90,06 & 471613,60 & 470888,23 & & 94,17 & 503241,71 & 498987,79 \\
\hline 12 & & 91,91 & 485850,09 & 485124,73 & & 94,94 & 509167,17 & 504913,26 \\
\hline 1 & \multirow{12}{*}{2008} & 93,83 & 500625,27 & 510585,52 & \multirow{12}{*}{2009} & 92,26 & 488543,49 & 519772,58 \\
\hline 2 & & 91,62 & 483618,43 & 493578,67 & & 92,42 & 489774,75 & 521003,85 \\
\hline 3 & & 91,70 & 484234,06 & 494194,31 & & 92,98 & 494084,18 & 525313,27 \\
\hline 4 & & 92,76 & 492391,19 & 502505,47 & & 93,89 & 501087,00 & 527812,16 \\
\hline 5 & & 94,53 & 506012,06 & 516126,33 & & 94,67 & 507089,41 & 533814,58 \\
\hline 6 & & 95,19 & 511091,02 & 521205,30 & & 95,72 & 515169,59 & 541894,76 \\
\hline 7 & & 97,61 & 529713,90 & 535058,73 & & 97,38 & 527943,96 & 555355,42 \\
\hline 8 & & 97,96 & 532407,29 & 537752,13 & & 98,62 & 537486,26 & 564897,73 \\
\hline 9 & & 96,26 & 519325,11 & 524669,94 & & 96,09 & 518016,89 & 545428,35 \\
\hline 10 & & 94,40 & 505011,65 & 515772,62 & & 98,85 & 539256,20 & 546477,56 \\
\hline 11 & & 94,77 & 507858,95 & 518619,92 & & 98,37 & 535562,41 & 542783,76 \\
\hline 12 & & 93,13 & 495238,49 & 505999,46 & & 97,67 & 530175,63 & 537396,98 \\
\hline 1 & \multirow{12}{*}{2010} & 96,59 & 521864,59 & 533420,81 & \multirow{12}{*}{2011} & 101,66 & 560880,29 & 581371,32 \\
\hline 2 & & 97,28 & 527174,42 & 538730,64 & & 98,06 & 533176,83 & 553667,86 \\
\hline 3 & & 101,37 & 558648,63 & 570204,85 & & 105,86 & 593200,99 & 613692,02 \\
\hline 4 & & 101,44 & 559187,30 & 562682,20 & & 102,19 & 564958,86 & 583670,39 \\
\hline 5 & & 100,9 & 555031,78 & 558526,68 & & 105,63 & 591431,05 & 610142,58 \\
\hline 6 & & 104,72 & 584428,23 & 587923,13 & & 107,23 & 603743,70 & 622455,23 \\
\hline 7 & & 100,93 & 555262,65 & 613301,74 & & 109,45 & 620827,50 & 657244,01 \\
\hline 8 & & 101,12 & 556724,77 & 614763,86 & & 103,1 & 571961,68 & 608378,19 \\
\hline 9 & & 92,32 & 489005,21 & 547044,30 & & 104,12 & 579810,99 & 616227,50 \\
\hline 10 & & 100,77 & 554031,38 & 576587,51 & & 107,59 & 606514,04 & 641657,98 \\
\hline 11 & & 101,72 & 561342,02 & 583898,15 & & 101,35 & 558494,72 & 593638,65 \\
\hline 12 & & 100,83 & 554493,11 & 577049,24 & & 102,89 & 570345,64 & 605489,57 \\
\hline
\end{tabular}


Data with 204 observations (continued)

\begin{tabular}{|c|c|c|c|c|c|c|c|c|}
\hline Month & Year & IP & $\begin{array}{c}\text { Initial } \\
\text { Estimation } \\
\text { (W) }\end{array}$ & $\begin{array}{l}\text { Monthly } \\
\text { GDP (Z) }\end{array}$ & Year & IP & $\begin{array}{c}\text { Initial } \\
\text { Estimation } \\
(W)\end{array}$ & $\begin{array}{l}\text { Monthly } \\
\text { GDP (Z) }\end{array}$ \\
\hline$(1)$ & (2) & (3) & (4) & (5) & (6) & (7) & $(8)$ & (9) \\
\hline 1 & \multirow{12}{*}{2012} & 102,76 & 569345,24 & 611934,34 & \multirow{12}{*}{2013} & 113,91 & 655149,00 & 660314,35 \\
\hline 2 & & 105,63 & 591431,05 & 634020,15 & & 112,31 & 642836,36 & 648001,70 \\
\hline 3 & & 102,46 & 567036,62 & 609625,71 & & 112,58 & 644914,11 & 650079,46 \\
\hline 4 & & 103,38 & 574116,39 & 613917,60 & & 114,12 & 656765,04 & 676681,50 \\
\hline 5 & & 108,31 & 612054,74 & 651855,95 & & 115,78 & 669539,41 & 689455,87 \\
\hline 6 & & 109,79 & 623443,93 & 663245,15 & & 113,34 & 650762,62 & 670679,22 \\
\hline 7 & & 111,41 & 635910,49 & 696428,73 & & 115,28 & 665691,71 & 703328,49 \\
\hline 8 & & 100,78 & 554108,34 & 614626,57 & & 113,37 & 650993,48 & 688630,17 \\
\hline 9 & & 109,61 & 622058,76 & 682577,00 & & 116,36 & 674002,75 & 711639,43 \\
\hline 10 & & 118,17 & 687931,43 & 670369,34 & & 118,05 & 687007,98 & 692411,31 \\
\hline 11 & & 114,13 & 656841,99 & 639279,91 & & 116,2 & 672771,48 & 678174,81 \\
\hline 12 & & 114,12 & 656765,04 & 639202,95 & & 117,36 & 681698,15 & 687101,48 \\
\hline 1 & \multirow{12}{*}{2014} & 117,32 & 681390,33 & 689375,73 & \multirow{12}{*}{2015} & 123,33 & 727639,72 & 723207,32 \\
\hline 2 & & 116,6 & 675849,64 & 683835,04 & & 119,67 & 699474,54 & 695042,14 \\
\hline 3 & & 116,8 & 677388,72 & 685374,12 & & 125,46 & 744030,93 & 739598,54 \\
\hline 4 & & 117,25 & 680851,66 & 697378,87 & & 127,11 & 756728,35 & 758900,02 \\
\hline 5 & & 120,16 & 703245,28 & 719772,50 & & 123,03 & 725331,10 & 727502,76 \\
\hline 6 & & 120,22 & 703707,01 & 720234,23 & & 126,26 & 750187,25 & 752358,92 \\
\hline 7 & & 117,05 & 679312,57 & 700459,29 & & 122,21 & 719020,86 & 737789,76 \\
\hline 8 & & 120,13 & 703014,42 & 724161,14 & & 127,01 & 755958,81 & 774727,70 \\
\hline 9 & & 127,74 & 761576,45 & 782723,17 & & 130,31 & 781353,64 & 800122,54 \\
\hline 10 & & 124,37 & 735642,94 & 725827,33 & & 132,07 & 794897,56 & 777069,33 \\
\hline 11 & & 121,73 & 715327,07 & 705511,46 & & 129,77 & 777198,13 & 759369,90 \\
\hline 12 & & 124,94 & 740029,32 & 730213,71 & & 126,84 & 754650,59 & 736822,37 \\
\hline 1 & \multirow{12}{*}{2016} & 126,5 & 752034,15 & 743999,95 & & & & \\
\hline 2 & & 128,5 & 767424,96 & 759390,76 & & & & \\
\hline 3 & & 128,67 & 768733,18 & 760698,98 & & & & \\
\hline 4 & & 127,28 & 758036,57 & 750482,80 & & & & \\
\hline 5 & & 131,69 & 791973,30 & 784419,54 & & & & \\
\hline 6 & & 136,3 & 827449,12 & 819895,36 & & & & \\
\hline 7 & & 132,93 & 801515,61 & 811498,45 & & & & \\
\hline 8 & & 134,72 & 815290,38 & 825273,23 & & & & \\
\hline 9 & & 130,37 & 781815,37 & 791798,22 & & & & \\
\hline 10 & & 132,15 & 795513,19 & 794320,22 & & & & \\
\hline 11 & & 132,34 & 796975,32 & 795782,35 & & & & \\
\hline 12 & & 132,3 & 796667,50 & 795474,53 & & & & \\
\hline
\end{tabular}


This page is intentionally left blank 